\title{
Optimal Reactive Power Compensation in Electric Transmission Line using STATCOM
}

\author{
Manish Pal ${ }^{1}$, Om Prakash Mahela ${ }^{2}$, Mukesh Kumar Gupta ${ }^{3}$ \\ ${ }^{I}$ (M.Tech Scholar, Jagannath University, Jaipur, India) \\ ${ }^{2}$ (Graduate Student Member IEEE \& Junior Engineer-I, RRVPNL, Jaipur, India) \\ ${ }^{3}$ (Assistant Professor, Department of Electrical Engineering, JNIT Jaipur, India)
}

\begin{abstract}
The increased electric power consumption causes transmission lines to be driven close to or even beyond their transfer capacities resulting in overloaded lines and congestions. FACTS devices provide an opportunity to resolve congestions by controlling active and reactive power flows as well as voltages. FACTS devices can be connected to a transmission line in various ways, such as in series, shunt, or a combination of series and shunt. Shunt FACTS devices are used for controlling transmission voltages, power flow, reducing reactive losses, and damping of power system oscillations for high power transfer levels. The SVC and STATCOM are two important shunt FACTS devices. In this paper the optimal location of STATCOM for reactive power compensation in electric transmission line to control power flows is investigated. The reactive power compensation of the STATCOM is studied with three different locations in the transmission line. The STATCOM is located at the receiving end, middle and at 2/3 distance from the sending end of the transmission line. The MATLAB simulation results show the relative performance.
\end{abstract}

Keywords - electric transmission line, FACTS devices, reactive power compensation, static synchronous compensator (STATCOM), shunt FACTS devices.

\section{INTRODUCTION}

Modern power system is a complex network comprising of numerous generators, transmission lines, variety of loads and transformers. Electric transmission system is the intermediate stage in the transfer of electrical energy from the central generating station to the consumers [1]. In highly complex and interconnected power systems, the power flows in some of the transmission lines are well below their normal limits, other lines are overloaded, which has an overall effect on deteriorating voltage profiles and decreasing system stability and security [2]. In present scenario, it becomes more important to control the power flow along the transmission lines to meet the needs of power transfer. The maximum power transfer of transmission system can be increased by shunt VAR compensation [3]. VAR compensation is defined as the management of reactive power to improve the performance of ac power systems. The concept of VAR compensation embraces a wide and diverse field of both system and customer problems, especially related with power quality issues, since most of power quality problems can be attenuated or solved with an adequate control of reactive power. Reactive power compensation in transmission systems also improves the stability of the ac system by increasing the maximum active power that can be transmitted [4].

FACTS devices are considered one of the best available technology that reduces the transmission congestion and allows better utilization of the existing grid infrastructure, along with many other benefits [5]. The location of FACTS devices can be based on static or dynamic performance of the system. Salim et al. [6] described the theory and simulation by MATLAB of FACTS devices used in the distributed power systems. Shunt FACTS devices are used for controlling transmission voltage, power flow, reducing reactive losses, and damping of power system oscillations for high power transfer levels. Anulekha et al. [7] investigates the enhancement in voltage stability margin as well as the improvement in the power transfer capability in a power system with the incorporation of fixed capacitors, STATCOM and SVC. The results obtained after Matlab simulation demonstrate the performance of shunt capacitors, SVC and STATCOM when connected to a system on the verge of unstability. In this paper, an analysis of active and reactive power flow in electric transmission line when compensated by STATCOM, the shunt FACTS device is carried out. The reactive power compensation of the STATCOM is studied with three different locations in the transmission line. The STATCOM is located at the receiving end, middle and at $2 / 3$ distance from the sending end of the transmission line. The MATLAB simulation results show the relative performance. This paper is organized as follows: section II describes the Static Synchronous Compensator (STATCOM). Section III presents the proposed model of transmission line for location of STATCOM under study. The simulation results and their discussion are presented in section IV. 


\section{STATIC SYNCHRONOUS COMPENSATOR}

The flexible AC transmission system (FACTS) has received much attention in the last two decades. It uses high current power electronic devices to control the voltage, power flow, stability etc. of a transmission system [8]. The pressure associated with economical and environmental constraints has forced the power utilities to meet the future demand by fully utilizing the existing resources of transmission facilities without building new lines. FACTS devices are very effective and capable of increasing the power transfer capability of a line, in so far thermal limits permit, while maintaining the same degree of stability [9]. The FACTS devices can be connected to a transmission line in various ways, such as in series, shunt, or a combination of series and shunt. The Shunt FACTS devices are used for controlling transmission voltage, power flow, reducing reactive losses, and damping of power system oscillations for high power transfer levels [10]. Shunt controller is a variable impedance, variable source, or a combination of these. All shunt controllers inject current into the system at the point of connection. As long as the injected current is in phase quadrature with the line voltage, the shunt controller only supplies or consumes variable reactive power. Any other phase relationship will involve handling of real power as well [11]. Static Synchronous Compensator (STATCOM) is one such controller.

The STATCOM is based on a solid state synchronous voltage source which generates a balanced set of three sinusoidal voltages at the fundamental frequency with rapidly controllable amplitude and phase angle [12]. As per IEEE definition STATCOM is defined as "A static synchronous generator operated as a shunt connected static VAR compensator who's Capacitive or Inductive output current can be controlled independent of the AC system voltage". The STATCOM controls transmission voltage by reactive shunt compensation. It can be based on a voltage-sourced or current-sourced converter [13]. Fig. 1 shows a one line diagram of STATCOM based on a voltage sourced converter and a current sourced converter. Normally a voltage source converter is preferred for most converter based FACTS controllers. STATCOM can be designed to be an active filter to absorb system harmonics.

Detailed analysis of STATCOM relating to its configuration, control as well as installation has been done in [14]. A comparison between shunt capacitor, SVC and STATCOM has been done to show their performance while connected to a Multi-bus system in [15]. STATCOM has been found to provide higher voltage stability margin as well as higher loading margin compared to other FACTS devices [16]. Devaraju et al. [17] presented electromagnetic transient studies for the distribution static compensator (D-STATCOM). Comprehensive results are presented to assess the performance of each device to mitigate the power quality problems. Whei-Min Lin et al. [18] used particle swarm optimization technique for optimal location of FACTS devices for voltage stability. A new model is proposed to improve existing power-electronics based model by using the Norton equivalent theorem. The proposed model can be integrated with the equivalent current injection power flow model. By using ECI algorithm and PSO, the optimal location of STATCOM can be obtained.

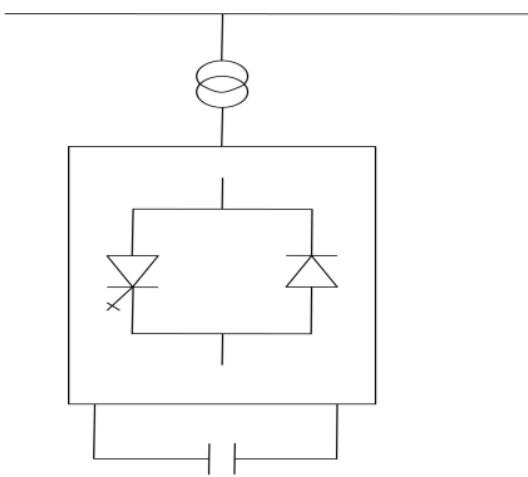

(a)

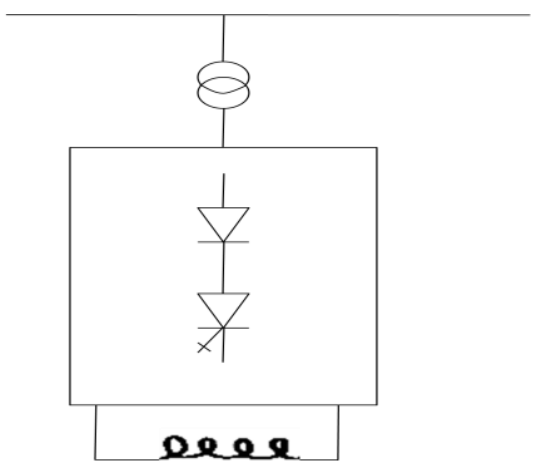

(b)

Fig. 1 (a) STATCOM based on voltage-sourced converter and (b) current-sourced converter

\section{PROPOSED POWER SYSTEM MOdEL}

The $150 \mathrm{Km}$ long $132 \mathrm{KV}$ transmission line is modeled. The sending end bus is taken as swing bus and receiving end bus is taken as load bus. The R-L load is connected to receiving end of the transmission line. Fig. 2(a) shows the transmission line without compensation. Fig. 2(b) shows the transmission line compensated by STATCOM at load end. The STATCOM is connected at the middle point of the transmission line as shown in Fig. 2(c). Fig. 2(d) shows the transmission line compensated at 2/3 distance from the sending end i.e. at distance of $100 \mathrm{~km}$ from the sending end and $50 \mathrm{~km}$ from the receiving end. 
Swing Bus

\begin{tabular}{|c|c|}
$\mathrm{R}+\mathrm{j} X$ & $\mathrm{P}+\mathrm{jQ}$ \\
\hline $150 \mathrm{KM}$ &
\end{tabular}

(a)

\begin{tabular}{|c|c|} 
Swing Bus \\
(b) & $\mathrm{R}+\mathrm{j} \times$ \\
STATCOM
\end{tabular}

Swing Bus

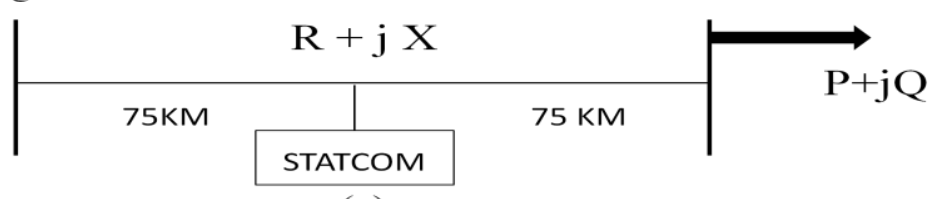

(c)

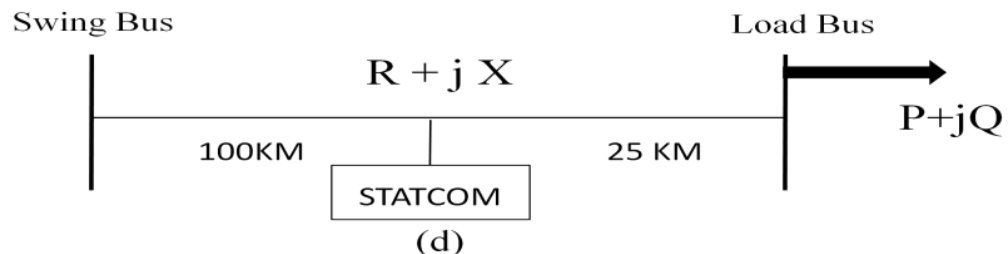

Fig.2 (a) Transmission Line without compensation (b) Transmission Line compensated by STATCOM at load end (c) Transmission Line compensated by STATCOM at middle point and (d) Transmission Line compensated by STATCOM at $2 / 3$ distance from sending end.

\section{SIMULATION RESULTS AND DISCUSSIONS}

The $132 \mathrm{KV}$ transmission line with length of $150 \mathrm{~km}$ is modeled in MATLAB/Simulink environment. The transmission line without compensation, compensated by STATCOM at load end, compensated by STATCOM at middle, and compensated by STATCOM at 2/3 distance from sending end is considered in study. The transmission line parameters used are shown in Table. I [19].

TABLE I

TRANSMISSION LINE PARAMETERS

\begin{tabular}{|c|c|c|}
\hline S. No. & Parameters of Transmission Line & Value of Parameters \\
\hline 1 & Positive sequence reactance & $1.30890 \mathrm{E}-3 \mathrm{H} / \mathrm{Km}$ \\
\hline 2 & Zero Sequence Reactance & $3.27225 \mathrm{E}-3 \mathrm{H} / \mathrm{Km}$ \\
\hline 3 & Positive sequence Resistance & $0.15850 \Omega / \mathrm{Km}$ \\
\hline 4 & Zero Sequence Resistance & $0.39625 \Omega / \mathrm{Km}$ \\
\hline 5 & Positive sequence Resistance & $9.13424 \mathrm{E}-9 \mathrm{~F} / \mathrm{Km}$ \\
\hline 6 & Zero Sequence Resistance & $3.27225 \mathrm{E}-9 \mathrm{~F} / \mathrm{Km}$ \\
\hline 7 & Transmission line length & $150 \mathrm{Km}$ \\
\hline 8 & Voltage of swing bus & $132 \mathrm{KV}$ \\
\hline 9 & Surge Impedance Loading & $45 \mathrm{MW}$ \\
\hline
\end{tabular}

\section{IV.1 Transmission Line without Compensation}

The transmission line without compensation shown in Fig. 2(a) is considered in study. The transmission line is simulated in Matlab/Simulink environment and the corresponding graphs of active and reactive power flow in the transmission line at sending end and receiving end are shown in Fig. 3 and Fig. 4 respectively. 


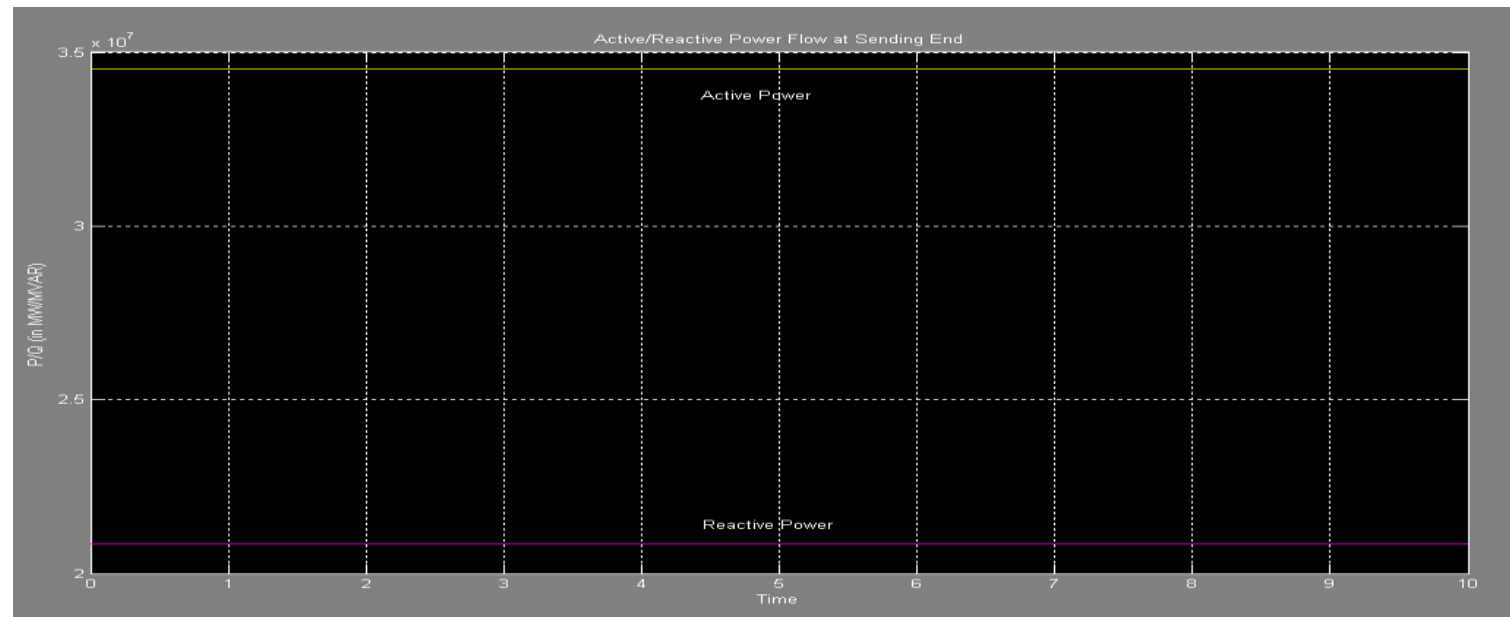

Fig. 3 Active and reactive power flow at sending end of transmission line without compensation

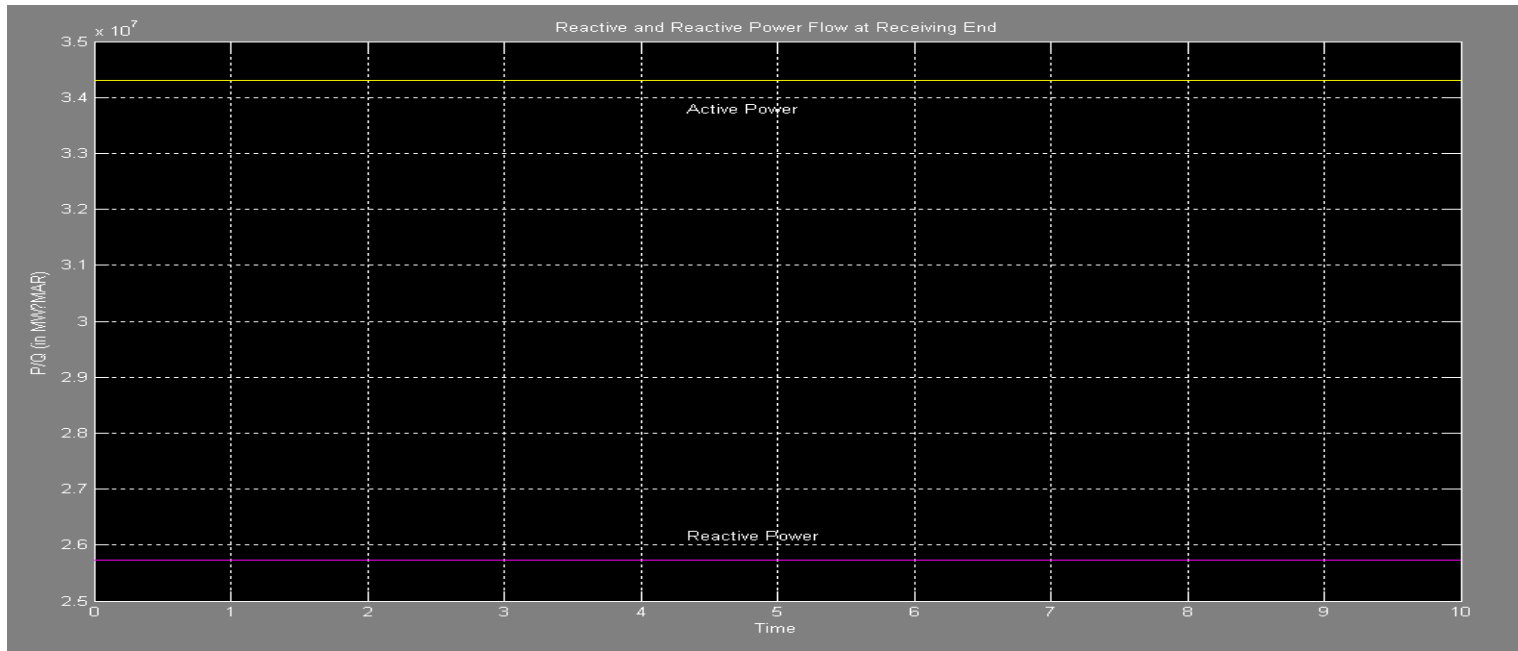

Fig. 4 Active and reactive power flow at receiving end of transmission line without compensation

\section{IV.2 Transmission Line Compensated by STATCOM at Load end}

The transmission line compensated by STATCOM at receiving end as shown in Fig. 2(b) is considered in study. The transmission line is simulated in Matlab/Simulink environment and the corresponding graphs of active and reactive power flow in the transmission line at sending end and receiving end are shown in Fig. 5 and Fig. 6 respectively.

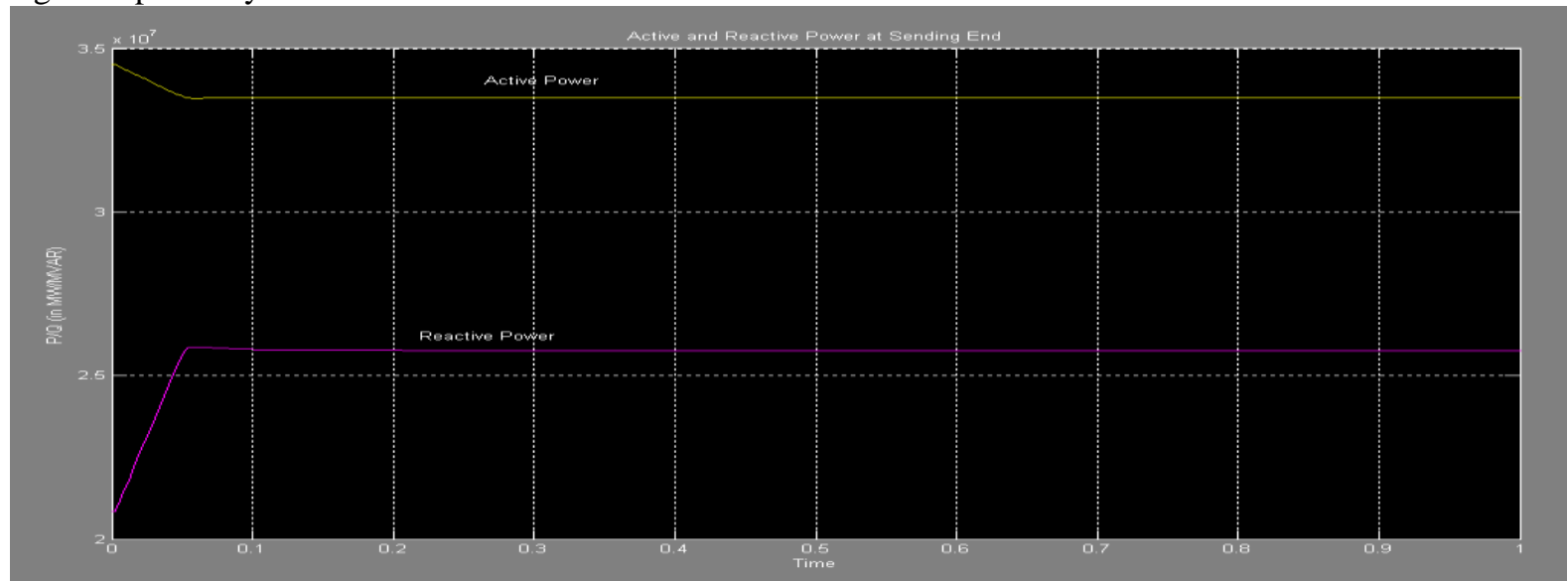

Fig. 5 Active and reactive power flow at sending end of transmission line compensated by STATCOM at load end 


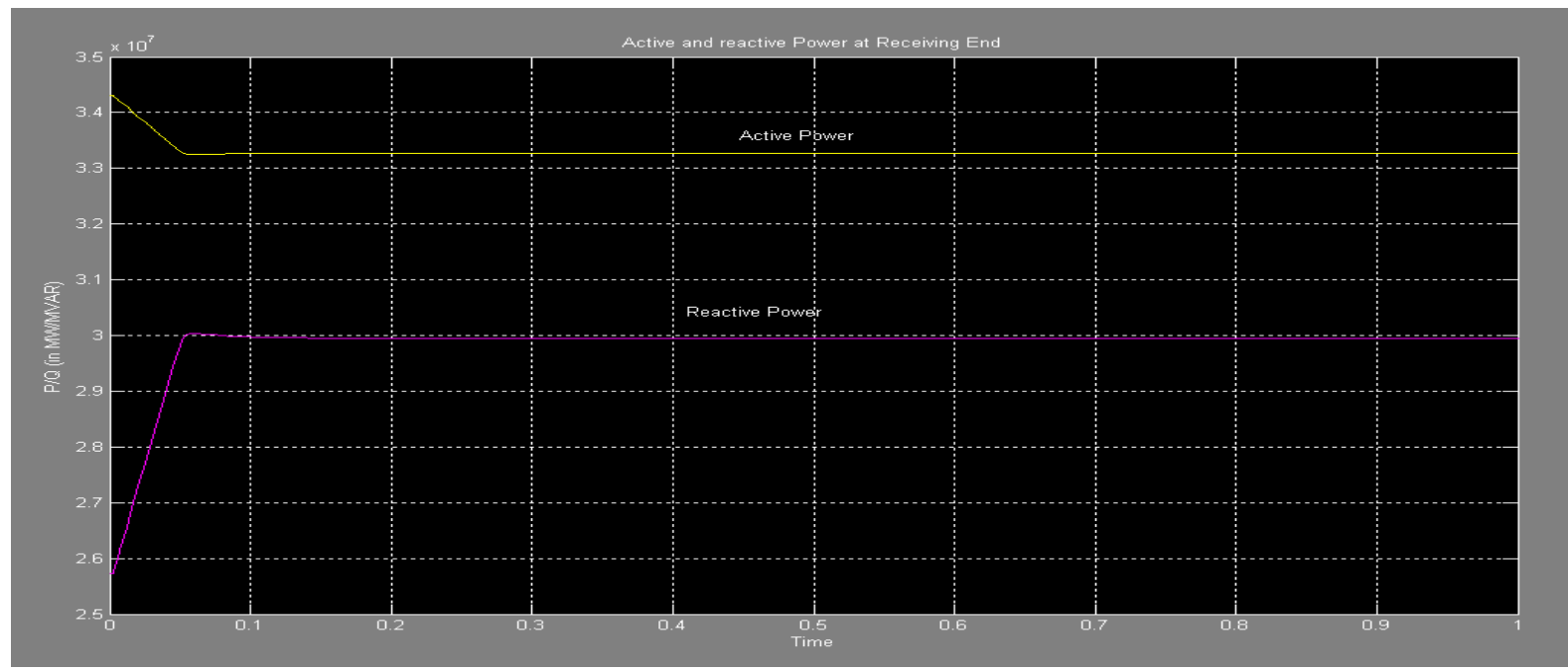

Fig. 6 Active and reactive power flow at receiving end of transmission line compensated by STATCOM at load end

\section{IV.3 Transmission Line Compensated by STATCOM at Middle}

The transmission line compensated by STATCOM at middle as shown in Fig. 2(c) is considered in study. The transmission line is simulated in Matlab/Simulink environment and the corresponding graphs of active and reactive power flow in the transmission line at sending end and receiving end are shown in Fig. 7 and Fig. 8 respectively.

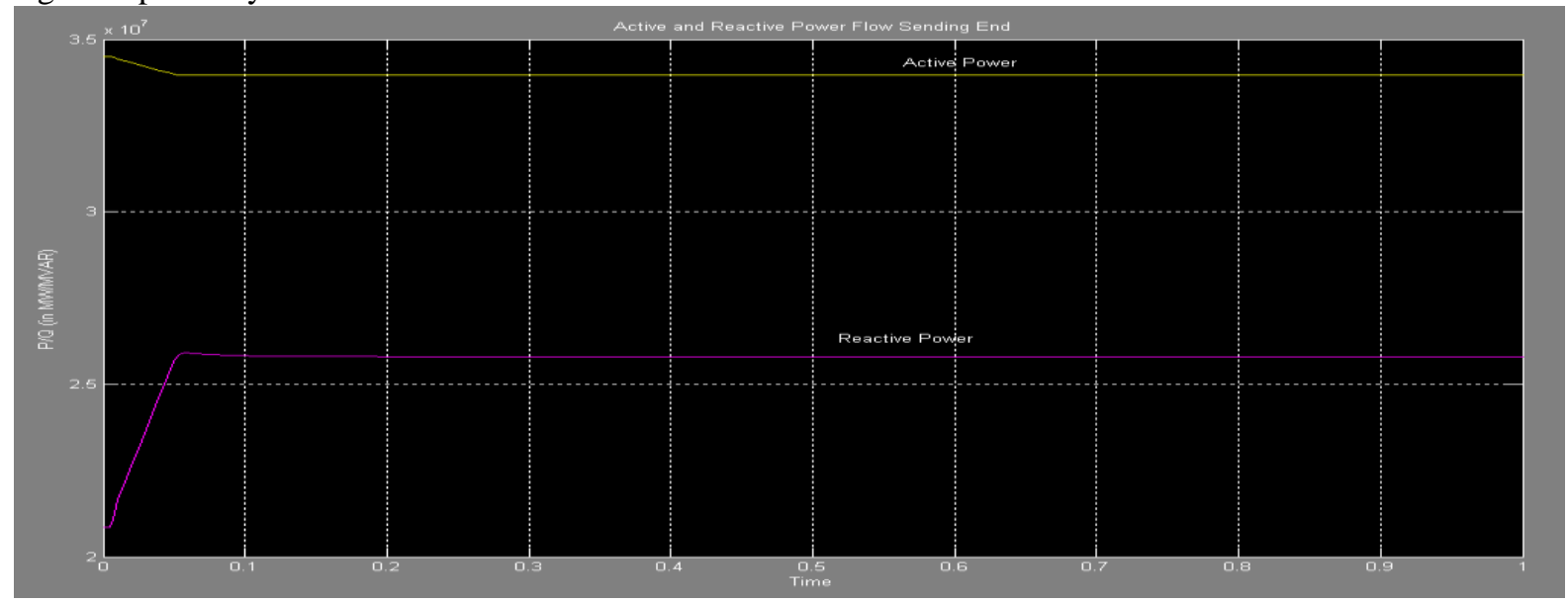

Fig. 7 Active and reactive power flow at sending end of transmission line compensated by STATCOM at middle

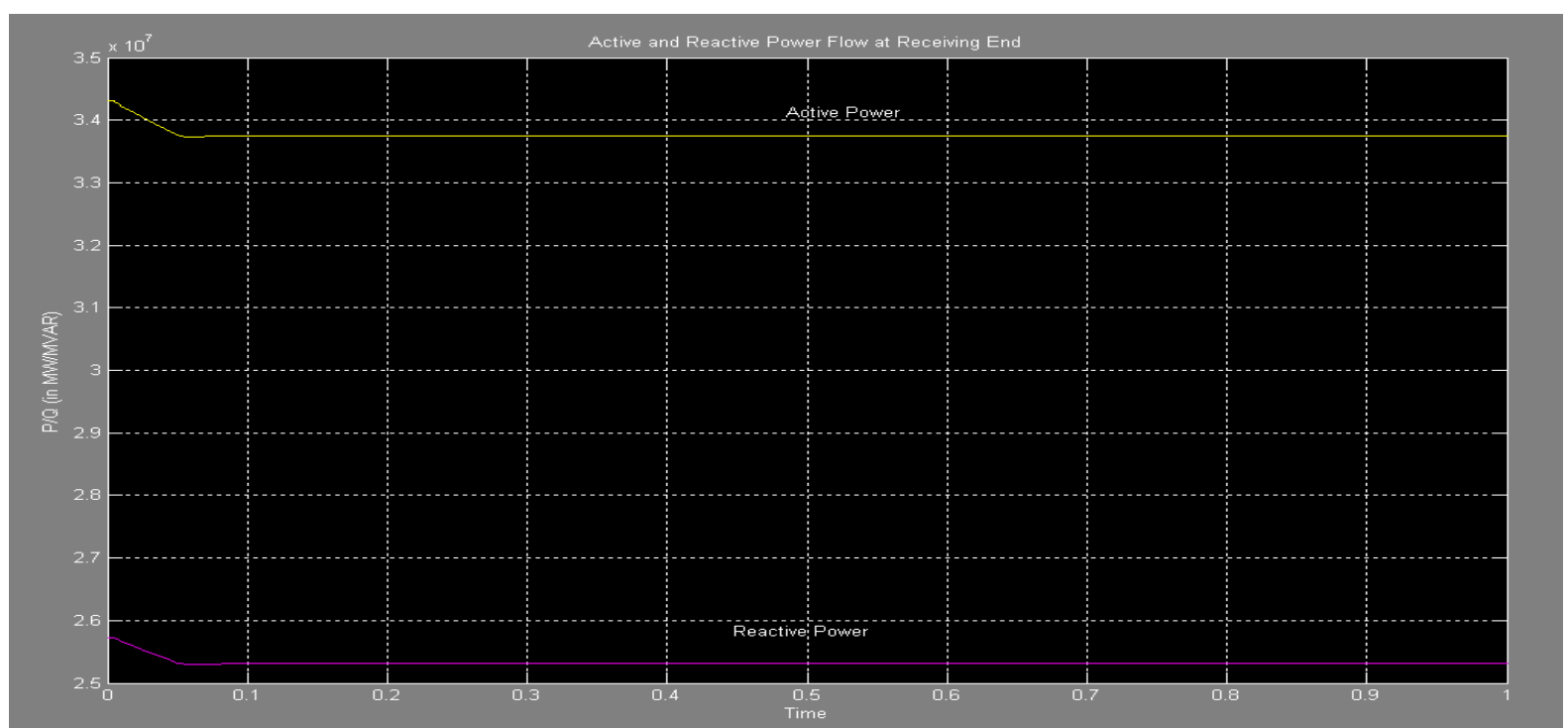

Fig. 8 Active and reactive power flow at receiving end of transmission line compensated by STATCOM at middle 


\section{IV.4 Transmission Line Compensated by STATCOM at 2/3 distance from sending end}

The transmission line compensated by STATCOM at 2/3 distance of line length from sending end as shown in Fig. 2(d) is considered in study. The transmission line is simulated in Matlab/Simulink environment and the corresponding graphs of active and reactive power flow in the transmission line at sending end and receiving end are shown in Fig. 9 and Fig. 10 respectively.

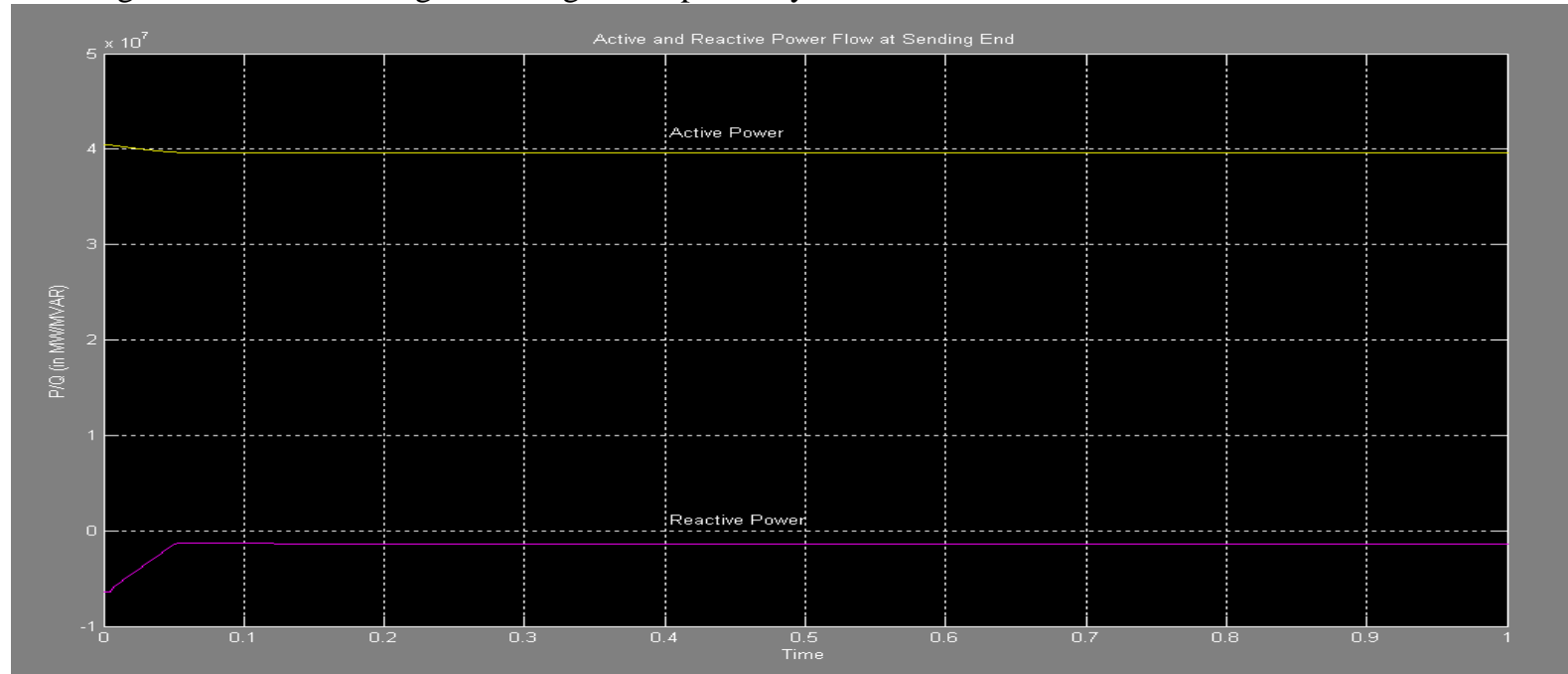

Fig. 9 Active and reactive power flow at sending end of transmission line compensated by STATCOM at $2 / 3$ distance from sending end

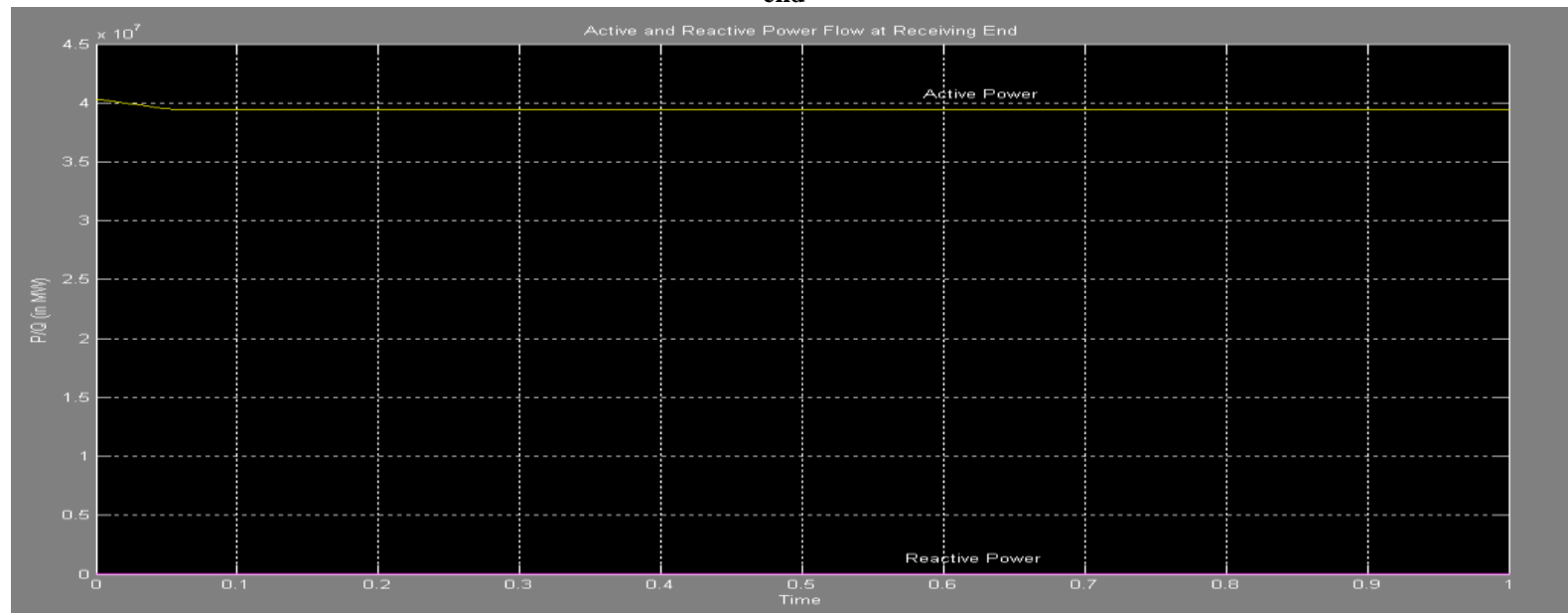

Fig. 10 Active and reactive power flow at receiving end of transmission line compensated by STATCOM at $2 / 3$ distance from sending end

Fig. 3 to Fig. 10 shows that the active power flow through the transmission line increases as well as transmission line losses decreases with compensation by STATCOM. Fig. 5 to Fig. 10 shows that the reactive power requirement is fully meet out by the STATCOM when it is located at distance of $2 / 3$ from the sending end of the transmission line and transmission lines is loaded near surge impedance loading and power flow through the line is active power. The maximum available capacity of the transmission line is used for active power transfer from sending end to the receiving end. In this location of the STATCOM, the active power loss in the transmission line is also minimum.

\section{CONCLUSION}

This paper investigates the opportunities to install STATCOM and its optimal location in electric transmission line for optimal reactive power compensation. The active and reactive power flow in the transmission line studied. The study shows that the transmission capacity of the line increases with compensation by STATCOM and reactive power flow in the line deceases in the line. The transmission line loss also decreases with compensation by the STATCOM. The maximum benefits of compensation are obtained when STATCOM is installed at $2 / 3$ distance from sending end i.e. at distance of $100 \mathrm{Km}$ from sending end and $50 \mathrm{Km}$ from receiving end of the $150 \mathrm{Km}$ long transmission line under study.. 


\section{REFERENCES}

[1] Om Prakash Mahela, Devendra Mittal, and Lalit Goyal, "Optimal capacitor placement techniques in transmission and distribution networks to reduce line losses and voltage stability enhancement: A review," IOSR-Journal of Electrical and Electronics Engineering, Vol. 3, Issue 4, Nov.-Dec. 2012, pp.01-08.

[2] D. Murli, and M. Rajaram, “Active and reactive power flow control using FACTS," International Journal of Computer Applications, Vol. 9, No. 8, November 2010, pp. 45-50.

[3] B.F.Wollenberg, "Transmission system reactive power compensation," IEEE Power Engineering Society Winter Meeting, Vol. 1, 2731 January 2002, pp. 506-508.

[4] Om Prakash Mahela, and Sheesh Ram Ola, "Optimal placement and sizing of HT shunt capacitors for transmission loss minimization and voltage profile improvement: The case of RRVPNL power grid," IAEME-International Journal of Electrical Engineering \& Technology, Vol. 4, Issue 2, March-April 2013, pp. 261-273.

[5] Naresh Acharya, and N. Mithulanathan, "Locating series FACTS devices for congestion management in deregulated electricity markets," Elsevier Electric Power Systems Research, Vol. 77, 2007, pp. 352-360.

[6] Salim. Haddad, A. Haddouche, and H. Bouyeda, "The use of FACTS devices in distributed power systems-modeling, interface, and case study," International Journal of Computer and Electrical Engineering, Vol. 1, No. 1, April 2009, pp. 56-60.

[7] Anulekha Saha, Priyanath Das, and Ajoy Kumar Chakraborty, "Performance analysis and comparison of various FACTS devices in power system," International Journal of Computer Applications, Vol. 46, No. 15, May 2012, pp.09-15.

[8] P.R. Sharma, Ashok Kumar, and Narender Kumar, "Optimal location for shunt connected FACTS devices in a series compensated long transmission line,” Turk Journal of Electrical Engineering, Vol. 15, No. 3, 2007, pp. 321-328.

[9] M.H. Haque, "Optimal location of shunt FACTS devices in long transmission line," IEE Proceedings on Generation Transmission \& Distribution, Vol. 147, No. 4, 2000, pp. 218-222.

[10] A.E. Hammad, "Analysis of power system stability enhancement by static var compensators," IEEE Transactions on Power Systems, Vol. 1, No. 4, 1986, pp. 222-227.

[11] Bhanu Chennapragada Venkata Krishan, Kotamarti S.B. Sankar, and Pindiprolu V. Haranath, "Power system operation and control using FACTS devices," CIRED $17^{\text {th }}$ International Conference on Electricity Distribution, Barcelona, 12-15 may 2003, Session 5 paper No. 19.

[12] Sidhartha Panda, and Ramnarayan N. Patel, "Improving power system transient stability with an off-centre location of shunt FACTS devices," Journal of Electrical Engineering, Vol. 57, No. 6, 2006, pp. 365-368.

[13] Narain G. Hingorani, Laszlo Gyugyi, Understanding FACTS Concepts and Technology, IEEE Press.

[14] D.J.Hanson, M.L. Woodhouse, C. Horwill, D.R. Monkhouse, and M.M. Osborne, "STATCOM: a new era of reactive components," Power Engineering Journal, June 2002.

[15] Arthit Sode-Yome, and N. Mithulananthan, "Comparison of shunt capacitor, SVC and STATCOM in static voltage stability margin enhancement," International Journal of Electrical and Electronics Engineering, Vol. 41, No. 3, pp. 158-171.

[16] Arthit Sode-Yome, and Nadarajah Mithulananthan, "Static voltage stability margin enhancement using STATCOM, TCSC and SSSC," IEEE/PES Transmission and Distribution Conference \& Exhibition, Asia and Pacific Dalian, China, 2005.

[17] T. Devaraju, V.C. Veera Reddy, and M.Vijay Kumar, "Modeling and simulation of custom power devices to mitigate power quality problems," International Journal of Engineering Science and Technology, Vol. 2, No. 6, 2010, pp. 1880-1885.

[18] Whei-Min Lin, Kai-Hung Lu, Chih-Ming Hong, and Chia-Sheg Tu, "Optimal location of FACTS for voltage stability using modified particle swarm optimization," Proceeding of the International Multi Conference of Engineers and Computer Scientists, 2012, Vol. II, IMEC 2012, March 14-16, 2012, Hong Kong.

[19] Om Prakash Mahela, and Sheesh Ram Ola, "Comparison of HT shunt capacitors and SVC for active and reactive power flow control in transmission line: The case of RRVPNL power grid," IASET-International Journal of Electrical and Electronics Engineering, Vol. 2, Issue 1, Feb 2013, pp. 49-58.

\section{BIOGRAPHIES}

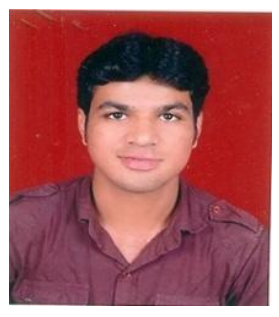

Manish Pal was born in Barisadri (Chittorgarh) in Rajasthan State of India on February 10, 1988. He studied at Jaipur Engineering College Kukas Jaipur and received the Electrical Engineering Degree from Rajasthan Technical University Kota, Rajasthan ,India in 2010. He is currently Pursuing M.Tech (Power System) from Jagannath University Jaipur, India.

He was Site Engineer in R.M.S.I Pvt ltd. From 2010 to 2011, he has been project engineer with Tech Martz Engineer (Bajaj Group) Jaipur since 2011. His special fields of interest are reactive power management in transmission and distribution networks and

FACTS devices.

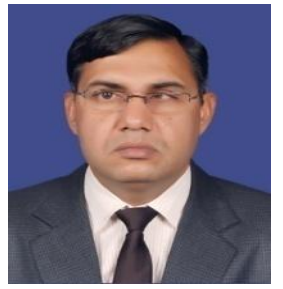

Om Prakash Mahela was born in Sabalpura (Kuchaman City) in the Rajasthan state of India, on April 11, 1977. He studied at Govt. College of Engineering and Technology (CTAE), Udaipur, and received the electrical engineering degree from Maharana Pratap University of Agriculture and Technology (MPUAT), Udaipur, India in 2002. He is currently pursuing M.Tech. (Power System) from Jagannath University, Jaipur, India.

From 2002 to 2004, he was Assistant Professor with the RIET, Jaipur. Since 2004, he has been Junior Engineer-I with the Rajasthan Rajya Vidhyut Prasaran Nigam Ltd., Jaipur, India. His special fields of interest are Transmission and Distribution (T\&D) grid operations, Power Electronics in Power System, Power Quality, Load Forecasting and Integration of Renewable Energy with Electric Transmission and Distribution Grid, Applications of AI Techniques in power system. He is an author of 22 International Journals and Conference papers. He is a Graduate Student Member of IEEE. He is member of IEEE Communications Society. He is Member of IEEE Power \& Energy Society. He is Reviewer of 
TJPRC International Journal of Electrical and Electronics Engineering Research. Mr. Mahela is recipient of University Rank certificate from MPUAT, Udaipur, India, in 2002.

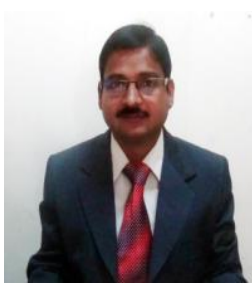

Mukesh Kumar Gupta completed his B.E. Degree in Electronic Instrumentation \& Control Engineering Branch in 1995 and M.E. Degree in Power System in 2009 from Engineering College Kota (RTU Kota) Rajasthan, India and he is pursuing Ph.D on Solar Energy from Jagannath University Jaipur, Rajasthan, India. 